\title{
Diabetes treatments and risk of heart failure, cardiovascular disease, and all cause mortality: cohort study in primary care
}

\author{
Julia Hippisley-Cox, Carol Coupland
}

Division of Primary Care, University Park, University of Nottingham, Nottingham NG2 7RD, UK

Correspondence to: J Hippisley-Cox

Julia.hippisley-cox@nottingham. ac.uk

Additional material is published online only. To view please visit the journal online.

Cite this as: BMJ 2016;354:i3477 http://dx.doi.org/10.1136/bmj.i3477

Accepted: 17 June 2016

\author{
ABSTRACT \\ OBJECTIVE \\ To assess associations between risks of cardiovascular \\ disease, heart failure, and all cause mortality and \\ different diabetes drugs in people with type 2 \\ diabetes, particularly newer agents, including gliptins \\ and thiazolidinediones (glitazones). \\ DESIGN \\ Open cohort study.

\section{SETTING} \\ 1243 general practices contributing data to the \\ QResearch database in England.
}

\section{PARTICIPANTS}

469688 people with type 2 diabetes aged 25-84 years between 1 April 2007 and 31 January 2015.

\section{EXPOSURES}

Diabetes drugs (glitazones, gliptins, metformin, sulphonylureas, insulin, other) alone and in combination.

\section{MAIN OUTCOME MEASURE}

First recorded diagnoses of cardiovascular disease, heart failure, and all cause mortality recorded on the patients' primary care, mortality, or hospital record. Cox proportional hazards models were used to estimate hazard ratios for diabetes treatments, adjusting for potential confounders.

RESULTS

During follow-up, 21308 patients (4.5\%) received prescriptions for glitazones and 32533 (6.9\%) received prescriptions for gliptins. Compared with

\section{WHAT IS ALREADY KNOWN ON THIS TOPIC}

Cardiovascular disease and heart failure are major causes of morbidity and mortality in people with type 2 diabetes

Several diabetes drugs have been associated with an unexpected increased risk of heart failure during clinical trials and post-marketing surveillance raising concerns about overall risks and benefits

There is a need to quantify risks of clinical outcomes in large representative populations of people with type 2 diabetes prescribed these drugs over longer periods

\section{WHAT THIS STUDY ADDS}

Clinically important differences in risk of cardiovascular disease, heart failure, and all cause mortality were found between different diabetes drugs alone and in combination

Compared with non-use of gliptins, gliptin use was significantly associated with an $18 \%$ decreased risk of all cause mortality, a $14 \%$ decreased risk of heart failure, and no significant change in risk of cardiovascular disease

Compared with non-use of glitazones, glitazones were significantly associated with a $23 \%$ decreased risk of all cause mortality, a $26 \%$ decreased risk of heart failure, and a $25 \%$ decreased risk of cardiovascular disease

non-use, gliptins were significantly associated with an $18 \%$ decreased risk of all cause mortality, a $14 \%$ decreased risk of heart failure, and no significant change in risk of cardiovascular disease; corresponding values for glitazones were significantly decreased risks of $23 \%$ for all cause mortality, $26 \%$ for heart failure, and $25 \%$ for cardiovascular disease. Compared with no current treatment, there were no significant associations between monotherapy with gliptins and risk of any complications. Dual treatment with gliptins and metformin was associated with a decreased risk of all three outcomes (reductions of $38 \%$ for heart failure, $33 \%$ for cardiovascular disease, and $48 \%$ for all cause mortality). Triple treatment with metformin, sulphonylureas, and gliptins was associated with a decreased risk of all three outcomes (reductions of $40 \%$ for heart failure, $30 \%$ for cardiovascular disease, and $51 \%$ for all cause mortality). Compared with no current treatment, monotherapy with glitazone was associated with a $50 \%$ decreased risk of heart failure, and dual treatment with glitazones and metformin was associated with a decreased risk of all three outcomes (reductions of $50 \%$ for heart failure, $54 \%$ for cardiovascular disease, and $45 \%$ for all cause mortality); dual treatment with glitazones and sulphonylureas was associated with risk reductions of $35 \%$ for heart failure and $25 \%$ for cardiovascular disease; triple treatment with metformin, sulphonylureas, and glitazones was associated with decreased risks of all three outcomes (reductions of $46 \%$ for heart failure, $41 \%$ for cardiovascular disease, and $56 \%$ for all cause mortality).

\section{CONCLUSIONS}

There are clinically important differences in risk of cardiovascular disease, heart failure, and all cause mortality between different diabetes drugs alone and in combination. Overall, use of gliptins or glitazones was associated with decreased risks of heart failure, cardiovascular disease, and all cause mortality compared with non-use of these drugs. These results, which do not account for levels of adherence or dosage information and which are subject to confounding by indication, might have implications for prescribing of diabetes drugs.

\section{Introduction}

Cardiovascular disease and heart failure are major causes of morbidity and mortality in people with type 2 diabetes. ${ }^{12}$ Once heart failure is present in people with diabetes, mortality is increased 10 -fold and five year survival is only $12.5 \%$, a prognosis worse than for metastatic breast cancer. ${ }^{2}$ Several diabetes drugs have been associated with an unexpected increase in risk of heart failure during both clinical trials ${ }^{3}$ and post-marketing 
surveillance raising concerns about the overall risks and benefits for people with diabetes. ${ }^{45}$

Following its launch in $2000,{ }^{6}$ rosiglitazone, the first drug in the "insulin sensitising" thiazolidinedione class, was associated with an increased rate of heart failure. ${ }^{5}$ This resulted in its withdrawal from Europe, India, New Zealand, and South Africa in 2010-11. Rosiglitazone is, however, still prescribed in the United States-a controversial decision ${ }^{7}$ informed by the open label "non-inferiority" rosiglitazone evaluated for cardiovascular outcomes in oral agent combination therapy for type 2 diabetes (RECORD) trial funded by the manufacturers of rosiglitazone (Avandia; GlaxoSmithKline). ${ }^{4}$ The RECORD study assessed cardiovascular outcomes in 2220 people prescribed rosiglitazone in combination with either metformin or sulphonylureas compared with 2227 prescribed both metformin and sulphonylureas between 2001 and 2008. Although the numbers of events were low, the trial reported an increased risk of heart failure with rosiglitazone and was unable to rule out an increased risk of myocardial infarction. ${ }^{4}$ The design, results, and interpretation of this trial have been heavily criticised. ${ }^{8}$

Pioglitazone is another thiazolidinedione that decreases blood glucose levels. The placebo controlled PROactive trial of pioglitazone ${ }^{9}$ was also controversial in its design and interpretation, largely because of the choice of composite endpoints. ${ }^{10}$ Although the trial failed to clearly show improved cardiovascular outcomes for patients, it reported increased hospital admissions for heart failure as an adverse effect, ${ }^{9}$ as did a subsequent meta-analysis of 8554 patients prescribed pioglitazone. ${ }^{11}$ Meanwhile, a Canadian cohort study comparing pioglitazone with rosiglitazone between 2002 and 2008 reported a lower risk of heart failure and death in pioglitazone users. ${ }^{12}$ Similarly, a US cohort study reported a lower risk of stroke, heart failure, and all cause mortality among patients prescribed pioglitazone compared with rosiglitazone. ${ }^{13}$ Pioglitazone continues to be prescribed in the United Kingdom and the US although it has been withdrawn elsewhere owing to concerns about an increased risk of bladder cancer. ${ }^{14}$

Dipeptidyl peptidase-4 (DPP-4) inhibitors, also known as gliptins, are a relatively new class of diabetes drug that are included in international guidelines ${ }^{15}$ as second line agents after metformin, although data on long term clinical benefits and safety are inconclusive. ${ }^{16}$ In a placebo controlled clinical trial, saxagliptin was associated with an unexpected $27 \%$ increase in admissions to hospital from heart failure. ${ }^{3}$ In the Examination of Cardiovascular Outcomes with Alogliptin versus Standard of Care (EXAMINE) trial, ${ }^{17}$ alogliptin did not significantly increase overall risk of hospital admissions for heart failure compared with placebo. Similarly, in the Trial Evaluating Cardiovascular Outcomes with Sitagliptin (TECOS) trial, sitagliptin was not associated with an increased risk of heart failure compared with placebo. ${ }^{18}$ Observational studies have also found inconsistent associations. Sitagliptin was associated with an increased risk of heart failure in a cohort study of 8288 Taiwanese patients using sitagliptin over 1.5 years. ${ }^{19}$ Conversely, a US cohort study of 8032 sitagliptin users showed no excess risk of hospital admission or death compared with users of other glucose lowering agents. ${ }^{20}$ Although heart failure was included within the composite endpoint, it was not evaluated separately. A meta-analysis of 25 trials of 7726 patients receiving sitagliptin or a comparator agent between 12 weeks and two years was undertaken by the manufacturers of sitagliptin (Januvia; MSD). ${ }^{21}$ The composite study endpoints included major adverse cardiovascular events (defined as ischaemic events or cardiovascular deaths), but the study did not specifically evaluate risk of heart failure. In summary, the findings from clinical trials and observational studies are inconsistent, which may reflect differences in study design, study duration, individual drugs, or outcome measures.

Uncertainty remains over the longer term comparative risks among patients prescribed different diabetes drugs, particularly gliptins and glitazones alone and in combination with other diabetes drugs. ${ }^{2223}$ Regulatory agencies have responded to this uncertainty by requiring evidence that new diabetes drugs are not associated with harmful increases in cardiovascular events rather than the more stringent requirement that the drugs result in evidence of clinical benefit. ${ }^{2425}$

Concerns have also been raised about the safety of sulphonylureas, an older class of oral diabetes drug, as these have been linked with increased adverse cardiovascular events in some ${ }^{5}$ but not all studies. ${ }^{26}$ The lifelong nature of diabetes, the noticeable increase in its incidence and prevalence, and prescribing recommendations in guidelines, ${ }^{15}$ mean that the number of people prescribed diabetes drugs is likely to increase. Given the impracticability and ethical difficulties of head-to-head trials comparing different agents, the risks of clinical outcomes need to be quantified in large representative populations of people prescribed these drugs over longer periods. This information, which is available from large longitudinal observational databases, can complement information from meta-analyses of clinical trials that, while valuable, are prone to publication bias and lack sufficient detail, duration of follow-up, or the power to make relevant comparisons for unintended effects. ${ }^{2123}$

We therefore carried out a cohort study using a large UK primary care database with linked general practitioner, mortality, and hospital admissions data to investigate the associations between different classes of diabetes drugs and the risks of heart failure, cardiovascular disease, and all cause mortality for people with type 2 diabetes. We were particularly interested in the risks associated with the newer agents, including glitazones and gliptins. In a companion paper we reported on a similar analysis examining the risks of microvascular complications (severe kidney disease, blindness, lower limb amputation), hyperglycaemia, and hypoglycaemia between different classes of diabetes drugs in people with type 2 diabetes. ${ }^{27}$

\section{Methods}

We did a population based open cohort study of people in England aged 25-84 years with a diagnosis of type 2 
diabetes. We used a large population of primary care patients derived from version 40 of the $Q$ Research database (www.qresearch.org). QResearch is a continually updated patient level pseudonymised database with event level data extending back to 1989. QResearch currently includes clinical and demographic data from over 1243 general practices in England and two practices in Scotland, covering a population of over 24 million patients, and collected in the course of routine healthcare by general practitioners and associated staff. The primary care data include demographic information, diagnoses, prescriptions, referrals, laboratory test results, and clinical values. Diagnoses are recorded using the Read code classification. ${ }^{28}$ QResearch has been used for a wide range of clinical research, including the assessment of unintended effects of commonly prescribed medicines. ${ }^{29-34}$ The primary care data are linked at individual patient level to hospital episode statistics and mortality records from the Office for National Statistics. Hospital episode statistics provides details of all National Health Service inpatient admissions since 1997, including primary and secondary causes coded using the ICD-10 (international classification of diseases, 10th revision) classifications and OPCS-4 (Office of Population Censuses and Surveys, fourth revision) codes for operations and interventions. ONS provides details of all deaths in England with primary and underlying causes, also coded using the ICD10 classification. Patient records are linked using a project specific pseudonymised NHS number, which is valid and complete for $99.8 \%$ of primary care patients, $99.9 \%$ of ONS mortality records, and $98 \%$ of hospital admissions records.

\section{Inclusion and exclusion criteria}

The study included all QResearch practices in England that had been using the Egton Medical Information Systems (EMIS) computer system for at least a year. We initially identified an open cohort of people aged 25-84 years registered with eligible practices between 1 April 2007 and 31 January 2015. This time interval was chosen because both pioglitazone and gliptins were available in the UK during the full study period. We then selected people with diabetes if they had a Read code for diabetes or more than one prescription for a diabetes drug.

We excluded people as having type 1 diabetes if they had received a diagnosis aged less than 35 and had been prescribed insulin. ${ }^{35}$ We also excluded patients without a postcode related deprivation score. For each patient we determined an entry date to the cohort, which was the latest of the following: date of diagnosis of diabetes, 25th birthday, date of registration with the practice plus one year, date on which the practice computer system was installed plus one year, and the beginning of the study period. To reduce bias we used an incident user design for people prescribed glitazones, gliptins (our main drugs of interest), or insulin. ${ }^{36}$ As in other studies, ${ }^{20}$ we defined incident users as people without a prescription for these drugs in the 12 months before the study entry date, and we excluded people who had received any of these drugs in the previous 12 months.
We included prevalent users of metformin or sulphonylureas in the study cohort; if we had excluded them the numbers of new users of glitazones and gliptins-our main exposures of interest-would have been substantially reduced because these drugs are usually prescribed after monotherapy with metformin or sulphonylureas. People with an existing diagnosis of an outcome of interest at the study entry date were also excluded from the analysis of that outcome. Patients were censored at the earliest date of the first recorded diagnosis of the outcome of interest, death, deregistration with the practice, last upload of computerised data, or the end date of the study (31 January 2015).

\section{Outcomes}

Our primary outcomes were incident heart failure, cardiovascular disease, and all cause mortality, recorded in either the patient's primary care record, linked hospital record, or mortality record.

\section{Definition of outcomes}

We used Read codes to identify recorded diagnoses of heart failure from the primary care records (G58\%, G5yy9, G5yyA, 662f, 662g, 662h, and 662i). To identify incident cases of heart failure from hospital and mortality records, we used ICD-10 clinical codes (I110, I130, I42, and I50). We used the earliest recorded date of heart failure on any of the three data sources as the index date for the diagnosis of heart failure.

Our definition of cardiovascular disease included coronary heart disease (angina and myocardial infarction), stroke, or transient ischaemic attacks but not peripheral vascular disease. The supplementary file lists the Read codes used for case identification on the primary care record. The ICD-10 codes used for case identification on the ONS death certificate or hospital admission records were: angina pectoris (I20), acute myocardial infarction (I22), complications after acute myocardial infarction (I23), other acute ischaemic heart disease (I24), chronic ischaemic heart disease (I25), and ischaemic stroke (I63, I64) or transient ischaemic attack (G45). We used the earliest recorded date of cardiovascular disease on any of the three data sources as the index date for the diagnosis of cardiovascular disease.

All cause mortality was defined by the status of death recorded in the general practice systems linked to the date and cause of death as recorded on the ONS mortality record.

\section{Exposure data}

Our primary exposures of interest were new use of gliptins and new use of glitazones during the study period. For each participant we extracted details of all individual prescriptions for all types of diabetes drug, including the prescription date and the type of drug. We partitioned the follow-up time into treatment periods, where each period corresponded to treatment with a particular type or combination of diabetes drug, or could be a period of no treatment with any diabetes drugs. If the patient changed to a different type of treatment or to a different combination of treatments, we 
classified that as a separate treatment period. For example, if a patient was prescribed metformin alone on entry to the cohort for 12 months and then was prescribed both glitazones and metformin for a further 24 months and then had a treatment free period for six months until they were censored, they would have three treatment periods (metformin only for 12 months, metformin and glitazones for 24 months, and no treatment for six months).

We determined the duration of each treatment period by calculating the number of days between the earliest issue date and the latest issue date plus 90 days for the type of treatment prescribed. If another treatment was added before the initial treatment was stopped then we calculated the duration of the treatment period on the initial treatment alone to be the number of days between the earliest issue date for the initial treatment and the earliest issue date for the next treatment. We added 90 days to the last prescription date as an estimate of the date on which the patient stopped treatment (the "stop date"), we made this assumption to allow for events that occur during a withdrawal period to be attributed to the drug rather than being counted as unexposed time. For the analysis, we used six binary exposure variables for each treatment period to indicate treatment with any of the diabetes drugs, grouped into six drug classes-glitazones (including rosiglitazone and pioglitazone), gliptins, metformin, sulphonylureas, insulin, and other oral diabetes drugs (including $\alpha$-glucosidase inhibitors, sodium-glucose cotransporter 2 inhibitors, glinides, guar). This accounted for patients receiving different combinations of these drugs during a treatment period. To further assess associations for different specific treatment combinations (such as dual treatment with metformin and glitazones) we also categorised treatments during each treatment period into one categorical variable with 21 mutually exclusive treatment categories, including a no current treatment group and 20 categories for monotherapy, dual treatment, and triple combinations of drugs.

\section{Confounding variables}

We considered confounding variables that were likely to be associated with the risk of the complications from diabetes ${ }^{20-40}$ or with the likelihood of receiving treatment with different diabetes drugs. These included age at study entry, sex, number of years since diabetes was diagnosed ( $<1$ year and 1-3, 4-6, 7-10, and $\geq 11$ years), ${ }^{40}$ calendar year, smoking status (non-smoker; former smoker; light smoker, 1-9 cigarettes/day; moderate smoker, 10-19 cigarettes/day; heavy smoker, $\geq 20$ cigarettes/day; not recorded), ethnic group (white/not recorded, Indian, Pakistani, Bangladeshi, other Asian, black African, black Caribbean, Chinese, other, including mixed), ${ }^{37}$ Townsend deprivation score, previous diabetes complications (severe kidney failure, $40 \geq 1$ episodes of hyperglycaemia, $\geq 1$ episodes of hypoglycaemia, lower limb amputation, blindness), comorbidities (cardiovascular disease ${ }^{40}$ (other than when cardiovascular disease was the outcome of interest), heart failure (other than when heart failure was the outcome of interest), peripheral vascular disease, valvular heart disease, chronic kidney disease, atrial fibrillation, ${ }^{37}$ hypertension, ${ }^{37}$ rheumatoid arthritis $\left.{ }^{37}\right)$ ), prescription drugs (statins, aspirin, anticoagulants, thiazides, angiotensin converting enzyme inhibitors, angiotensin receptor blockers, calcium channel blockers), and clinical values (body mass index $\mathrm{kg} / \mathrm{m},{ }^{240}$ cholesterol to high density lipoprotein cholesterol ratio, ${ }^{37}$ systolic blood pressure (mm Hg), ${ }^{37}$ serum creatinine level, glycated haemoglobin $\mathrm{A1}_{\mathrm{c}}(\mathrm{mmol} / \mathrm{mol}) .{ }^{4041}$ We evaluated confounders at the start of each treatment period for comorbidities, previous complications, other prescribed drugs, smoking status, and clinical values. For comorbidities and previous complications, we identified whether patients had a diagnosis recorded before the relevant treatment period. For prescribed drugs, we defined patients as treated at the start of the relevant period of diabetes drug treatment if they had at least two prescriptions for the other type of drug, including one in the 28 days before the treatment period and one after the start date. For smoking status and continuous variables (systolic blood pressure, body mass index, creatinine level, cholesterol to high density lipoprotein cholesterol ratio, and haemoglobin $\mathrm{A} 1_{\mathrm{c}}$ ), we used the most recent recorded value immediately before the relevant treatment period.

\section{Statistical analysis}

Using Cox proportional hazards models we assessed the associations between the six different classes of diabetes drugs and risk of each of our three outcomes, adjusting for potential confounding variables. Rather than using a competing risks analysis we used the Cox model as it is considered more appropriate for analyses of causes such as in this study, whereas competing risks analyses tend to be more useful for prediction modelling or estimating absolute risks. ${ }^{42-44}$ To account for patients starting and stopping different diabetes treatments and changing between treatments, we included use of different diabetes drugs as time varying exposures. In the analysis, we calculated unadjusted and adjusted hazard ratios for the six different classes of diabetes drug (each as a binary variable indicating use or no use), with adjustment for the confounding variables and the other classes of diabetes drugs. We also calculated unadjusted and adjusted hazard ratios for the mutually exclusive treatment combinations comparing each treatment category with no current treatment. To determine whether there were significant differences between classes or individual drugs, we carried out Wald's tests. We tested for interactions between the six different drug classes and age, sex, haemoglobin $\mathrm{A}_{\mathrm{c}}$, and body mass index. We used multiple imputation with chained equations to replace missing values for continuous values and smoking status and used these values in our main analyses. ${ }^{45-47}$ We did this for each of the study outcomes and in the imputation model included the censoring indicator for the outcome, the log of survival time, all the confounding variables, and the diabetes drug treatment variables. Before imputation we log transformed body 


\section{Box 1: Types of models used in study}

- Model A: diabetes drug classes adjusted for age, sex, ethnicity, deprivation, calendar year, duration of diabetes, plus other diabetes drugs

- Model B: model A plus comorbidities (hypertension, cardiovascular disease, heart failure, atrial fibrillation, chronic kidney disease, rheumatoid arthritis, valvular heart disease, peripheral vascular disease) plus previous complications (hypoglycaemia, hyperglycaemia, amputation, severe kidney failure, blindness) plus use of other drugs (statins, aspirin, anticoagulants, thiazides, angiotensin converting enzyme inhibitors or angiotensin receptor blockers, calcium channel blockers)

- Model C (primary analysis model): model B plus clinical values (body mass index, cholesterol to high density lipoprotein cholesterol ratio, systolic blood pressure, serum creatinine level, haemoglobin $\mathrm{A}_{\mathrm{c}}$ )

- Model D: model C plus interaction terms

- Model E: treatment combinations categorical variable plus confounders in model C (models compared with no treatment and with metformin monotherapy)

- Model F: model C with prevalent users of sulphonylureas excluded

- Model G: model E with prevalent users of sulphonylureas excluded

mass index, haemoglobin $\mathrm{A}_{c}$, creatinine level, and cholesterol to high density lipoprotein cholesterol ratio, as they had skewed distributions. We carried out five imputations, and combined the results using Rubin's rules.

To evaluate the robustness of our results and assess the impact of confounding variables we added the confounding variables to our model in blocks and compared the adjusted hazard ratios. Box 1 lists the models we assessed.

We also carried out a sensitivity analysis where we excluded prevalent users of sulphonylureas from the study cohort so that the hazard ratios for sulphonylureas are based on incident users, and we fitted the models $\mathrm{F}$ and $\mathrm{G}$ (see box 1).

We used all the available data in the database to maximise the power and generalisability of the results. $P$ values less than 0.01 (two tailed) were considered as significant and hazard ratios of 1.10 or more or 0.90 or less as clinically important. STATA (version 13.1) was used for all analyses.

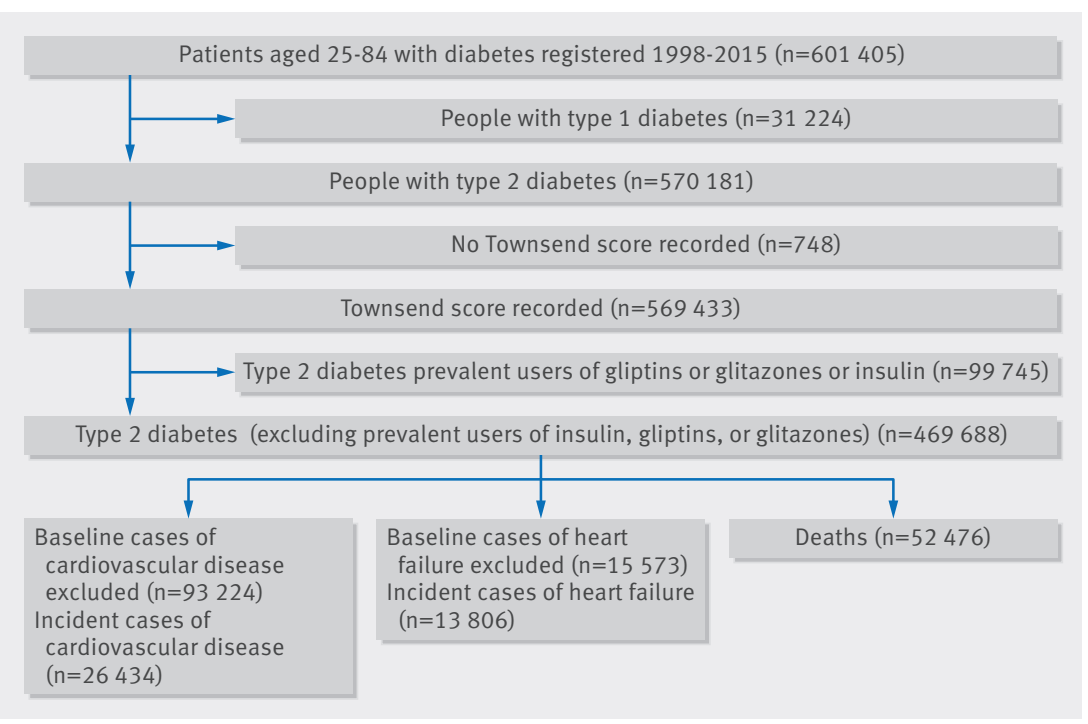

Fig 1 | Flow of people through study

\section{Patient involvement}

Patients were not involved in setting the research question, in the outcome measures, in the design, or in the implementation of the study. Patient representatives from the QResearch advisory board have written the information for patients on the QResearch website about the use of the database for research. They have also advised on dissemination, including the use of lay summaries describing the research and its results.

\section{Results}

Overall, 1243 practices contributing to QResearch in England met the inclusion criteria. A cohort of 601405 patients aged 25-84 years with diabetes was identified (fig 1). We sequentially excluded 31224 people with type 1 diabetes (5.1\%), 748 (0.1\%) without a Townsend deprivation score, and 99745 prescribed glitazones, gliptins, or insulin in the 12 months before the study entry date, leaving 469688 patients with type 2 diabetes in the study cohort. Figure 1 also shows the numbers of patients with each outcome at baseline who were excluded from the analysis of that outcome, as well as the numbers of incident outcomes observed during follow-up.

\section{Baseline characteristics}

In total 274324 (58.4\%) of the patients in the study cohort received prescriptions for one or more diabetes drugs during follow-up: 21308 (4.5\%) for glitazones, 32533 (6.9\%) for gliptins, 256024 (54.5\%) for metformin, 134570 (28.7\%) for sulphonylureas, 19791 (4.2\%) for insulin, and 12062 (2.6\%) for other oral diabetes drugs.

Table 1 shows the characteristics of patients who started each of the six classes of diabetes drugs during follow-up based on the last recorded value before the drug was first prescribed (or at study entry for patients already prescribed sulphonylureas, metformin, or other diabetes drugs at baseline). The groups were similar for most characteristics except for higher levels of comorbidities other than hypertension in patients prescribed insulin, and lower levels of prescriptions for statins and aspirin in patients prescribed metformin compared with the other drugs.

Table 2 shows levels of recording and mean values for haemoglobin $A 1_{c}$, body mass index, cholesterol to high density lipoprotein cholesterol ratio, systolic blood pressure, and serum creatinine level before starting treatment. The highest levels of recording were for haemoglobin $A 1_{c}$, which were in excess of $97 \%$ for all six drug groups. Lowest levels of recording were for cholesterol to high density lipoprotein cholesterol ratios, which were more than $84 \%$ for all drug groups. Overall, at least $82 \%$ of patients had complete data for each clinical value across all drug groups. Apart from higher mean levels of haemoglobin $\mathrm{A}_{\mathrm{c}}$ in patients before use of insulin or the group of other diabetes drugs, and higher levels of creatinine among those prescribed sulphonylureas or insulin, the mean values were similar across the six groups. Supplementary table 1 shows mean values before starting the 20 different treatment combinations. The mean values for haemoglobin $A 1_{c}$ 


\begin{tabular}{|c|c|c|c|c|c|c|}
\hline Characteristics & Glitazones & Gliptins & Metformin & Sulphonylureas & Insulin & Other diabetes drugs \\
\hline Total No of patients exposed & 21308 & 32533 & 256024 & 134570 & 19791 & 12062 \\
\hline Median No of years exposed & 4.5 & 5.7 & 4.8 & 4.9 & 5.9 & 4.9 \\
\hline Mean (SD) age at study entry & $63.0(11.9)$ & $63.3(12.1)$ & $64.6(13.1)$ & $66.2(12.9)$ & $64.5(12.7)$ & $60.0(11.9)$ \\
\hline Mean (SD) Townsend score & $0.4(3.5)$ & $0.5(3.5)$ & $0.6(3.6)$ & $0.6(3.6)$ & $0.5(3.6)$ & $0.8(3.6)$ \\
\hline Male & $12658(59.4)$ & $18871(58.0)$ & $146690(57.3)$ & $79284(58.9)$ & $11499(58.1)$ & $6509(54.0)$ \\
\hline \multicolumn{7}{|l|}{ Ethnicity: } \\
\hline Ethnicity recorded & $19130(89.8)$ & $29396(90.4)$ & $228962(89.4)$ & $119507(88.8)$ & $17264(87.2)$ & $10947(90.8)$ \\
\hline White or not recorded & $17112(80.3)$ & $26104(80.2)$ & $204915(80.0)$ & $107537(79.9)$ & $17001(85.9)$ & $10135(84.0)$ \\
\hline Indian & $997(4.7)$ & $1662(5.1)$ & $11732(4.6)$ & $5978(4.4)$ & $476(2.4)$ & $420(3.5)$ \\
\hline Pakistani & $811(3.8)$ & $1132(3.5)$ & $7425(2.9)$ & $3972(3.0)$ & $389(2.0)$ & $290(2.4)$ \\
\hline Bangladeshi & $586(2.8)$ & $713(2.2)$ & $7282(2.8)$ & $3980(3.0)$ & $370(1.9)$ & $374(3.1)$ \\
\hline Other Asian & $476(2.2)$ & $720(2.2)$ & $5873(2.3)$ & $2947(2.2)$ & $234(1.2)$ & $164(1.4)$ \\
\hline Caribbean & $473(2.2)$ & $795(2.4)$ & $6376(2.5)$ & $3700(2.7)$ & $549(2.8)$ & $278(2.3)$ \\
\hline Black African & $392(1.8)$ & $676(2.1)$ & $5715(2.2)$ & $2977(2.2)$ & $350(1.8)$ & $161(1.3)$ \\
\hline Chinese & $84(0.4)$ & $95(0.3)$ & $983(0.4)$ & $513(0.4)$ & $36(0.2)$ & $34(0.3)$ \\
\hline Other & $377(1.8)$ & $636(2.0)$ & $5723(2.2)$ & $2966(2.2)$ & $386(2.0)$ & $206(1.7)$ \\
\hline \multicolumn{7}{|l|}{ Smoking status: } \\
\hline Smoking status recorded & $21215(99.6)$ & $32399(99.6)$ & $255186(99.7)$ & $134080(99.6)$ & $19569(98.9)$ & $12003(99.5)$ \\
\hline Non-smoker & $11374(53.4)$ & $17116(52.6)$ & $132634(51.8)$ & $69849(51.9)$ & $9393(47.5)$ & $6126(50.8)$ \\
\hline Former smoker & $6252(29.3)$ & $9725(29.9)$ & $78935(30.8)$ & $41438(30.8)$ & $6142(31.0)$ & $3726(30.9)$ \\
\hline Light smoker & $2170(10.2)$ & $3358(10.3)$ & $25678(10.0)$ & $13846(10.3)$ & $2413(12.2)$ & $1252(10.4)$ \\
\hline Moderate smoker & $730(3.4)$ & $1121(3.4)$ & $9395(3.7)$ & $4661(3.5)$ & $832(4.2)$ & $441(3.7)$ \\
\hline Heavy smoker & $689(3.2)$ & 1079 (3.3) & 8544 (3.3) & $4286(3.2)$ & $789(4.0)$ & $458(3.8)$ \\
\hline \multicolumn{7}{|l|}{ Comorbidities: } \\
\hline Cardiovascular disease & $2962(13.9)$ & $5325(16.4)$ & $48066(18.8)$ & $28895(21.5)$ & $4596(23.2)$ & $1992(16.5)$ \\
\hline Heart failure & $302(1.4)$ & $737(2.3)$ & $6943(2.7)$ & $5069(3.8)$ & $960(4.9)$ & $374(3.1)$ \\
\hline Peripheral vascular disease & $1008(4.7)$ & $1576(4.8)$ & $12458(4.9)$ & $8467(6.3)$ & $1519(7.7)$ & $544(4.5)$ \\
\hline Valvular heart disease & $379(1.8)$ & $914(2.8)$ & $7378(2.9)$ & $4606(3.4)$ & 765 (3.9) & $292(2.4)$ \\
\hline Hypertension & $12520(58.8)$ & $19293(59.3)$ & $150219(58.7)$ & $80776(60.0)$ & $11117(56.2)$ & $7310(60.6)$ \\
\hline Atrial fibrillation & $929(4.4)$ & $1980(6.1)$ & $17327(6.8)$ & $10574(7.9)$ & $1890(9.5)$ & $657(5.4)$ \\
\hline Chronic kidney disease & $388(1.8)$ & $593(1.8)$ & $3067(1.2)$ & $4183(3.1)$ & $1165(5.9)$ & $224(1.9)$ \\
\hline Rheumatoid arthritis & $719(3.4)$ & $1237(3.8)$ & $9718(3.8)$ & $5382(4.0)$ & $842(4.3)$ & $460(3.8)$ \\
\hline \multicolumn{7}{|l|}{ Previous complications: } \\
\hline Severe kidney disease & $54(0.3)$ & $74(0.2)$ & $509(0.2)$ & $825(0.6)$ & $213(1.1)$ & $36(0.3)$ \\
\hline Blindness & $260(1.2)$ & $383(1.2)$ & $3715(1.5)$ & $2404(1.8)$ & $360(1.8)$ & $170(1.4)$ \\
\hline Amputation & $85(0.4)$ & $125(0.4)$ & $1239(0.5)$ & $894(0.7)$ & $161(0.8)$ & $65(0.5)$ \\
\hline$\geq 1$ previous episode of hypoglycaemia & $288(1.4)$ & $286(0.9)$ & $2247(0.9)$ & $1946(1.4)$ & $337(1.7)$ & $215(1.8)$ \\
\hline$\geq 1$ previous episode of hyperglycaemia & $7921(37.2)$ & $10054(30.9)$ & $68839(26.9)$ & $46341(34.4)$ & $7279(36.8)$ & $3914(32.4)$ \\
\hline \multicolumn{7}{|l|}{ Other drugs: } \\
\hline anticoagulant & $642(3.0)$ & $1419(4.4)$ & $9409(3.7)$ & $5989(4.5)$ & $1344(6.8)$ & $540(4.5)$ \\
\hline Thiazides & $3444(16.2)$ & $4346(13.4)$ & $31291(12.2)$ & $16972(12.6)$ & $2386(12.1)$ & $1844(15.3)$ \\
\hline ACE inhibitors & $9318(43.7)$ & $12939(39.8)$ & $83847(32.7)$ & $48960(36.4)$ & $7750(39.2)$ & $5362(44.5)$ \\
\hline Angiotension receptor blockers & $3399(16.0)$ & $4895(15.0)$ & $28629(11.2)$ & $16976(12.6)$ & $2633(13.3)$ & $2088(17.3)$ \\
\hline Calcium channel blockers & $5613(26.3)$ & $8105(24.9)$ & $55674(21.7)$ & $32141(23.9)$ & $5034(25.4)$ & $3328(27.6)$ \\
\hline Statins & $15512(72.8)$ & $21383(65.7)$ & $137574(53.7)$ & $77865(57.9)$ & $12640(63.9)$ & $8451(70.1)$ \\
\hline Aspirin & $7890(37.0)$ & $9684(29.8)$ & $68013(26.6)$ & 41647 (30.9) & $7057(35.7)$ & $4096(34.0)$ \\
\hline
\end{tabular}

tended to be higher for patients starting triple treatment (as high values tend to trigger changes in treatment).

\section{Risks associated with use of each diabetes drug group}

Table 3 shows the number of incident cases of each outcome for patients' periods of use of each of the six treatment groups during follow-up. Importantly, the treatment groups in table 3 are not mutually exclusive-for example, the rows for glitazones include any use of glitazones, whether as monotherapy, dual treatment, or triple treatment. Similarly, the adjusted hazard ratios for model $\mathrm{C}$ shown in table 3 give an overall risk for the use of each drug group compared with non-use of that drug group, having adjusted for use of other diabetes drugs and the potential confounders listed in the footnote.

For our main exposures of interest we found that compared with non-use, glitazones were significantly associated with a $23 \%$ decreased risk of all cause 


\begin{tabular}{|c|c|c|c|c|c|c|}
\hline Clinical variables & Glitazones & Gliptins & Metformin & Sulphonylureas & Insulin & Other diabetes drugs \\
\hline Total No of patients exposed & 21308 & 32533 & 256024 & 134570 & 19791 & 12062 \\
\hline \multicolumn{7}{|l|}{ Variables recorded (\%): } \\
\hline Haemoglobin $\mathrm{A} 1_{c}$ & $21251(99.7)$ & $32474(99.8)$ & 253219 (98.9) & $133170(99.0)$ & $19255(97.3)$ & $12022(99.7)$ \\
\hline Body mass index & $21120(99.1)$ & $32224(99.1)$ & $252290(98.5)$ & $132477(98.4)$ & $19436(98.2)$ & $11749(97.4)$ \\
\hline Cholesterol to HDL ratio & $18264(85.7)$ & $29307(90.1)$ & $224504(87.7)$ & $115991(86.2)$ & $16723(84.5)$ & $10619(88.0)$ \\
\hline Systolic blood pressure & $21306(100.0)$ & $32529(100.0)$ & $255892(99.9)$ & $134487(99.9)$ & $19765(99.9)$ & $12057(100.0)$ \\
\hline Creatinine level & 21288 (99.9) & 32509 (99.9) & $255381(99.7)$ & $134244(99.8)$ & $19655(99.3)$ & $12044(99.9)$ \\
\hline Total recorded & $18097(84.9)$ & $29010(89.2)$ & 220119 (86.0) & $113843(84.6)$ & $16270(82.2)$ & $10340(85.7)$ \\
\hline \multicolumn{7}{|l|}{ Mean (SD) values: } \\
\hline Haemoglobin $\mathrm{A} 1_{c}(\mathrm{mmol} / \mathrm{mol})$ & $66.8(18.9)$ & $68.4(18.4)$ & $61.4(18.7)$ & $64.9(19.9)$ & $75.4(22.7)$ & 70.9 (19.6) \\
\hline Body mass index $\left(\mathrm{kg} / \mathrm{m}^{2}\right)$ & $31.7(6.0)$ & $31.7(5.9)$ & $30.6(5.9)$ & $30.1(5.8)$ & $30.2(6.1)$ & $34.1(6.6)$ \\
\hline Cholesterol to HDL ratio & $3.8(1.3)$ & $3.9(1.3)$ & $3.8(1.3)$ & $3.8(1.3)$ & $4.0(1.4)$ & $4.0(1.3)$ \\
\hline Systolic blood pressure $(\mathrm{mm} \mathrm{Hg})$ & $133.1(14.8)$ & $132.3(14.7)$ & $132.5(15.3)$ & $132.8(15.9)$ & $131.7(16.9)$ & $132.5(14.9)$ \\
\hline Creatinine level & $87.1(33.7)$ & 84.9 (33.3) & $84.8(30.1)$ & $92.1(47.7)$ & $99.3(62.0)$ & $83.5(34.6)$ \\
\hline
\end{tabular}

$\mathrm{HDL}=$ high density lipoprotein cholesterol.

Values represent those recorded before starting drugs or at study entry for prevalent users. Treatment groups not mutually exclusive.

\begin{tabular}{|c|c|c|c|c|}
\hline Outcomes and drugs & No of cases & Person years & Rate per 10000 & $\begin{array}{l}\text { Adjusted hazard } \\
\text { ratio }(95 \% \mathrm{Cl})\end{array}$ \\
\hline \multicolumn{5}{|l|}{ All cause mortality: } \\
\hline Glitazones & 597 & 55916 & 106.8 & $0.77(0.71 \text { to } 0.84)^{\star}$ \\
\hline Gliptins & 996 & 71524 & 139.3 & $0.82(0.77 \text { to } 0.88)^{*}$ \\
\hline Metformin & 17109 & 1066516 & 160.4 & $0.59(0.58 \text { to } 0.60)^{\star}$ \\
\hline Sulphonylureas & 12717 & 506719 & 251.0 & $1.10(1.07$ to 1.12$) \dagger$ \\
\hline Insulin & 2529 & 57875 & 437.0 & $1.47(1.41$ to 1.53$) \dagger$ \\
\hline Other diabetes drugs & 350 & 28293 & 123.7 & $0.82(0.73 \text { to } 0.91)^{\star}$ \\
\hline \multicolumn{5}{|l|}{ Heart failure: } \\
\hline Glitazones & 308 & 55051 & 56.0 & $0.74(0.66 \text { to } 0.83)^{*}$ \\
\hline Gliptins & 421 & 68724 & 61.3 & $0.86(0.78 \text { to } 0.95)^{\star}$ \\
\hline Metformin & 6785 & 1029331 & 65.9 & $0.70(0.68 \text { to } 0.73)^{\star}$ \\
\hline Sulphonylureas & 4415 & 481339 & 91.7 & 1.04 (1.00 to 1.08$) \ddagger$ \\
\hline Insulin & 686 & 52634 & 130.3 & $1.32(1.22$ to 1.43$) \dagger$ \\
\hline Other diabetes drugs & 192 & 26950 & 71.2 & $0.92(0.79$ to 1.06$) \neq$ \\
\hline \multicolumn{5}{|l|}{ Cardiovascular disease: } \\
\hline Glitazones & 699 & 47374 & 147.6 & $0.75(0.69 \text { to } 0.81)^{\star}$ \\
\hline Gliptins & 912 & 56414 & 161.7 & $0.94(0.88$ to 1.00$) \neq$ \\
\hline Metformin & 14218 & 834914 & 170.3 & $0.76(0.74 \text { to } 0.78)^{\star}$ \\
\hline Sulphonylureas & 7999 & 378816 & 211.2 & 1.00 (0.97 to 1.03$) \neq$ \\
\hline Insulin & 985 & 39870 & 247.1 & $1.23(1.15$ to 1.31$) \dagger$ \\
\hline Other diabetes drugs & 396 & 22152 & 178.8 & 0.95 (0.86 to 1.05$) \neq$ \\
\hline \multicolumn{5}{|c|}{$\begin{array}{l}\text { Hazard ratios adjusted for: sex; age; calendar year; duration since diagnosis of diabetes (five levels); ethnicity } \\
\text { (nine levels); Townsend deprivation score; smoking status (five levels); use of other diabetes drugs, } \\
\text { anticoagulants, thiazides, angiotensin converting enzyme inhibitors, angiotensin receptor blockers, calcium } \\
\text { channel blockers, statins, or aspirin, previous complications (blindness, hyperglycaemia, hypoglycaemia, } \\
\text { amputation, severe kidney failure); hypertension; cardiovascular disease; atrial fibrillation; chronic renal } \\
\text { disease; rheumatoid arthritis; valvular heart disease; peripheral vascular disease; body mass index; systolic } \\
\text { blood pressure; haemoglobin A1; serum creatinine level; cholesterol to high density lipoprotein ratio. } \\
\text { *Significantly decreased hazard ratio. } \\
\text { tSignificantly increased hazard ratio. } \\
\text { fNon-significant results. }\end{array}$} \\
\hline
\end{tabular}

mortality, a 26\% decreased risk of heart failure, and a $25 \%$ decreased risk of cardiovascular disease; and compared with non-use, gliptins were significantly associated with an $18 \%$ decreased risk of all cause mortality, a $14 \%$ decreased risk of heart failure, and no significant association with risk of cardiovascular disease.

In addition, for the other diabetes drug groups we found that compared with non-use, metformin was associated with a significantly decreased risk of all three outcomes-41\% decreased risk of all cause mortality, a 30\% decreased risk of heart failure, and a $24 \%$ decreased risk of cardiovascular disease; compared with non-use, sulphonylureas were significantly associated with a $10 \%$ increased risk of all cause mortality; compared with non-use, insulin was associated with a $47 \%$ increased risk of all cause mortality, a 32\% increased risk of heart failure, and a $23 \%$ increased risk of cardiovascular disease; and compared with non-use, the other diabetes drugs group was significantly associated with an $18 \%$ decreased risk of all cause mortality.

For all cause mortality, we found significant interactions between glitazones and both age and haemoglobin $\mathrm{A1}_{\mathrm{c}}$ (see supplementary tables 2a and b; model D) where the reduced risk of all cause mortality associated with glitazone use became less marked with both increasing age and increasing levels of haemoglobin $\mathrm{A} 1_{c}$. Similarly, for cardiovascular disease, there were significant interactions between glitazones and haemoglobin $\mathrm{A} 1_{\mathrm{c}}$, where the reduced risk of cardiovascular disease associated with glitazone use became less marked with increasing levels of haemoglobin $\mathrm{A}_{\mathrm{c}}$.

We found similar interactions in both magnitude and direction for gliptins and both age and haemoglobin $\mathrm{A}_{\mathrm{c}}$ for all cause mortality and between gliptins and haemoglobin $\mathrm{A}_{\mathrm{c}}$ for cardiovascular disease.

Supplementary table 2 also shows the results from analyses with confounders added in separate blocks (models A and B). Generally, including comorbidities and previous complications in the model (model B) tended to result in similar hazard ratios for gliptins and glitazones (compared with model A). Further inclusion of clinical values (table 3: model C) only resulted in small changes to the hazard ratios. The sensitivity analysis excluding prevalent users of sulphonylureas at study entry showed increases in adjusted hazard ratios for all cause mortality and cardiovascular disease for insulin (see supplementary table 2: model E compared with model C) but similar hazard ratios for the other diabetes drug groups for all three outcomes. 


\begin{tabular}{|c|c|c|c|c|c|c|}
\hline \multirow[b]{2}{*}{ Variables } & \multicolumn{2}{|l|}{ Heart failure } & \multicolumn{2}{|c|}{ Cardiovascular disease } & \multicolumn{2}{|c|}{ All cause mortality } \\
\hline & No of cases & Person years & No of cases & Person years & No of cases & Person years \\
\hline Periods with no treatment & 5317 & 675598 & 9769 & 541445 & 27367 & 707183 \\
\hline \multicolumn{7}{|l|}{ Monotherapy: } \\
\hline Metformin & 3334 & 570230 & 7376 & 464698 & 9815 & 589353 \\
\hline Sulphonylureas & 1211 & 82466 & 1752 & 59918 & 5654 & 90846 \\
\hline Insulin & 220 & 14802 & 290 & 11408 & 1349 & 16859 \\
\hline Glitazones & 9 & 1671 & 24 & 1352 & 48 & 1704 \\
\hline Gliptins & 23 & 2361 & 43 & 1874 & 112 & 2560 \\
\hline Other diabetes drugs & 18 & 1474 & 31 & 1168 & 72 & 1618 \\
\hline \multicolumn{7}{|l|}{ Dual treatment: } \\
\hline Metformin and sulphonylureas & 2439 & 304023 & 4772 & 242136 & 5350 & 316576 \\
\hline Metformin and insulin & 189 & 17328 & 262 & 13153 & 399 & 18540 \\
\hline Metformin and glitazones & 75 & 17825 & 160 & 15742 & 163 & 18024 \\
\hline Metformin and gliptins & 114 & 23530 & 263 & 19898 & 257 & 24218 \\
\hline Metformin and other diabetes drugs & 60 & 9009 & 119 & 7,479 & 85 & 9375 \\
\hline Sulphonylureas and insulin & 94 & 3756 & 100 & 2558 & 369 & 4593 \\
\hline Sulphonylureas and glitazones & 37 & 3444 & 59 & 2691 & 114 & 3564 \\
\hline Sulphonylureas and gliptins & 47 & 4068 & 71 & 2988 & 164 & 4451 \\
\hline Sulphonylureas and other diabetes drugs & 21 & 973 & 22 & 765 & 46 & 1096 \\
\hline \multicolumn{7}{|l|}{ Triple treatment: } \\
\hline Metformin, sulphonylureas, and insulin & 123 & 10893 & 212 & 8209 & 283 & 11593 \\
\hline Metformin, sulphonylureas, and glitazones & 133 & 24790 & 344 & 21295 & 209 & 25168 \\
\hline Metformin, sulphonylureas, and gliptins & 181 & 30617 & 412 & 24885 & 355 & 31762 \\
\hline Metformin, sulphonylureas, and other & 60 & 9636 & 127 & 7902 & 87 & 10070 \\
\hline All other drug combinations & 101 & 13519 & 226 & 11160 & 178 & 14127 \\
\hline Total & 13806 & 1822013 & 26434 & 1462724 & 52476 & 1903280 \\
\hline
\end{tabular}

\section{Risks associated with different treatment} combinations

Table 4 provides a more detailed breakdown of 21 mutually exclusive treatment categories, including a no current treatment group, which included 0.7 million person years free of use of any diabetes drug. The table shows the number of events for each clinical outcome for each of the treatment categories.

Table 5 shows the corresponding adjusted hazard ratios for each treatment group category compared with no current treatment. The key significant findings are (all compared with periods of no diabetes drug treatment):

- There were no significant associations between monotherapy with gliptins and risk of any of the three outcomes. Dual treatment with gliptins and metformin was associated with a decreased risk of all three outcomes (reductions of 38\% for heart failure, 33\% for cardiovascular disease, and $48 \%$ for all cause mortality). Triple treatment with metformin, sulphonylureas, and gliptins was associated with a decreased risk of all three outcomes (reductions of $40 \%$ for heart failure, $30 \%$ for cardiovascular disease, and 51\% for all cause mortality).

- Monotherapy with glitazones was associated with a $50 \%$ decreased risk of heart failure. Dual treatment with metformin and glitazones was associated with a decreased risk of all three outcomes (reductions of 50\% for heart failure, 54\% for cardiovascular disease, and $45 \%$ for all cause mortality). Dual treatment with sulphonylureas and glitazones was associated with a decreased risk of two outcomes (reductions of 35\% for heart failure and $25 \%$ for cardiovascular disease). Triple treatment with metformin, sulphonylureas, and glitazones was associated with a decreased risk of all three outcomes (reductions of $46 \%$ for heart failure, $41 \%$ for cardiovascular disease, and 56\% for all cause mortality).

Table 6 shows the results for the different treatment combinations compared with metformin treatment alone (rather than compared with periods of no treatment as previously). The key findings for our two exposures of interest are:

- Monotherapy with gliptins was associated with a $50 \%$ increased risk of cardiovascular disease and an $86 \%$ increased risk of all cause mortality; dual treatment with metformin and gliptins was associated with a decreased risk of two outcomes (reductions of 13\% for cardiovascular disease and $20 \%$ for all cause mortality); dual treatment with sulphonylureas and gliptins was associated with a $44 \%$ increased risk of all cause mortality and a borderline $27 \%$ increased risk of cardiovascular disease; triple treatment with metformin, sulphonylureas, and gliptins was associated with a $24 \%$ decreased risk of all cause mortality compared with metformin alone.

- Monotherapy with glitazones was not associated with an increased or decreased risk of any outcome compared with metformin alone; dual treatment with metformin and glitazones was associated with a decreased risk of two outcomes (reductions of $26 \%$ for heart failure and $40 \%$ for cardiovascular disease) and a borderline $14 \%$ decreased risk in all cause mortality; dual treatment with sulphonylureas and glitazones was associated with a 50\% increased risk of all cause mortality; triple treatment with metformin, sulphonylureas, 


\begin{tabular}{|c|c|c|c|}
\hline \multirow[b]{2}{*}{ Outcomes by treatment } & \multicolumn{3}{|c|}{ Adjusted hazard ratio $(95 \% \mathrm{Cl})$} \\
\hline & Heart failure & Cardiovascular disease & All cause mortality \\
\hline No current treatment (reference) & 1.00 & 1.00 & 1.00 \\
\hline \multicolumn{4}{|l|}{ Monotherapy: } \\
\hline Metformin & $0.68(0.65 \text { to } 0.71)^{\star}$ & $0.76\left(0.74\right.$ to $0.79^{*}$ & $0.64\left(0.63\right.$ to $0.66^{\star}$ \\
\hline Sulphonylureas & $1.00(0.94$ to 1.07$) \ddagger$ & $1.00(0.95$ to 1.05$) \ddagger$ & $1.24(1.20$ to 1.28$) \dagger$ \\
\hline Insulin & $1.26(1.10$ to 1.44$) \dagger$ & $1.22(1.08$ to 1.37$) \dagger$ & $1.64(1.55$ to 1.74$) \dagger$ \\
\hline Glitazones & 0.50 (0.26 to $0.97^{\star}$ & $0.79(0.53$ to 1.18$) \neq$ & $0.89(0.67$ to 1.18$) \neq$ \\
\hline Gliptins & $0.87(0.58$ to 1.31$) \ddagger$ & $1.14(0.85$ to 1.54$) \ddagger$ & $1.20(1.00$ to 1.44$) \ddagger$ \\
\hline Other diabetes drugs & $0.92(0.58$ to 1.46$) \neq$ & $1.12(0.79$ to 1.59$) \ddagger$ & $1.06(0.84$ to 1.33$) \ddagger$ \\
\hline \multicolumn{4}{|l|}{ Dual treatment: } \\
\hline Metformin and sulphonylureas & $0.74(0.70 \text { to } 0.78)^{\star}$ & $0.75(0.73 \text { to } 0.78)^{\star}$ & $0.62(0.60 \text { to } 0.64)^{\star}$ \\
\hline Metformin and insulin & 1.08 (0.93 to 1.25$) \neq$ & $0.89(0.78$ to 1.01$) \ddagger$ & $0.76(0.69 \text { to } 0.84)^{*}$ \\
\hline Metformin and glitazones & $0.50(0.40 \text { to } 0.63)^{\star}$ & $0.46(0.39 \text { to } 0.54)^{*}$ & $0.55(0.47 \text { to } 0.64)^{*}$ \\
\hline Metformin and gliptins & $0.62(0.52 \text { to } 0.75)^{\star}$ & $0.67(0.59 \text { to } 0.75)^{\star}$ & $0.52(0.46 \text { to } 0.59)^{\star}$ \\
\hline Metformin and other diabetes drugs & $0.74(0.57 \text { to } 0.95)^{\star}$ & $0.73(0.61 \text { to } 0.88)^{*}$ & $0.46(0.37 \text { to } 0.57)^{\star}$ \\
\hline Sulphonylureas and insulin & $1.18(0.96$ to 1.45$) \ddagger$ & $1.18(0.96$ to 1.44$) \neq$ & $1.49(1.35$ to 1.66$) \dagger$ \\
\hline Sulphonylureas and glitazones & $0.65(0.47 \text { to } 0.89)^{\star}$ & $0.75(0.58 \text { to } 0.98)^{\star}$ & $0.96(0.80$ to 1.16$) \neq$ \\
\hline Sulphonylureas and gliptins & 0.88 (0.66 to 1.17$) \ddagger$ & $0.97(0.76$ to 1.22$) \neq$ & $0.92(0.79$ to 1.08$) \ddagger$ \\
\hline Sulphonylureas and other diabetes drugs & $1.46(0.95$ to 2.24$) \ddagger$ & $1.02(0.67$ to 1.55$) \ddagger$ & $1.33(1.00$ to 1.78$) \ddagger$ \\
\hline \multicolumn{4}{|l|}{ Triple treatment: } \\
\hline Metformin, sulphonylureas, and insulin & 0.91 (0.76 to 1.09)‡ & 0.95 (0.82 to 1.09$) \ddagger$ & 0.98 (0.87 to 1.10$) \ddagger$ \\
\hline Metformin, sulphonylureas, and glitazones & $0.54(0.45 \text { to } 0.64)^{*}$ & $0.59(0.53 \text { to } 0.66)^{\star}$ & $0.44(0.38 \text { to } 0.50)^{\star}$ \\
\hline Metformin, sulphonylureas, and gliptins & $0.60(0.52 \text { to } 0.70)^{\star}$ & $0.70(0.63 \text { to } 0.78)^{\star}$ & $0.49(0.44 \text { to } 0.55)^{\star}$ \\
\hline Metformin, sulphonylureas, and other diabetes drugs & $0.60(0.46 \text { to } 0.77)^{\star}$ & $0.62(0.52 \text { to } 0.74)^{\star}$ & $0.46(0.37 \text { to } 0.57)^{\star}$ \\
\hline All other drug combinations & $0.72(0.59 \text { to } 0.88)^{\star}$ & $0.82(0.72 \text { to } 0.94)^{\star}$ & $0.68(0.58 \text { to } 0.79)^{\star}$ \\
\hline \multicolumn{4}{|c|}{$\begin{array}{l}\text { *Significantly decreased. } \\
\text { +Significantly increased. } \\
\text { fNon-significant. } \\
\text { Hazard ratios adjusted for: sex; age; calendar year; duration since diagnosis of diabetes (five levels); ethnicity (nine levels); Townsend deprivation score; } \\
\text { smoking status (five levels); use of other diabetes drugs, anticoagulant thiazides, angiotensin coverting enzyme inhibitors, angiotensin receptor } \\
\text { blockers, calcium channel blockers, statins, and aspirin; previous complications (blindness, hyperglycaemia, hypoglycaemia, amputation, severe kidney } \\
\text { failure); hypertension; cardiovascular disease; atrial fibrillation; chronic renal disease; rheumatoid arthritis; valvular heart disease; peripheral vascular } \\
\text { disease; body mass index; systolic blood pressure; haemoglobin A1; serum creatinine level; cholesterol to high density lipoprotein cholesterol ratio. }\end{array}$} \\
\hline
\end{tabular}

and glitazones was associated with a decreased risk of all three outcomes (reductions of 21\% for heart failure, $22 \%$ for cardiovascular disease, and $32 \%$ for all cause mortality) compared with metformin alone.

Supplementary table 3 shows the results for the different treatment combinations compared with periods of no treatment, having dropped prevalent users of sulphonylureas at study entry (model G). Incident use of sulphonlyureas, whether alone or in combination with insulin as dual or triple treatment, was associated with a substantial increased risk of all cause mortality of $50 \%, 171 \%$, and $87 \%$, respectively. Monotherapy with sulphonylureas was associated with a $12 \%$ increased risk of cardiovascular disease and a 16\% increased risk of heart failure. Triple treatment with sulphonlyureas, metformin, and insulin was associated with a $42 \%$ increased risk of heart failure. Overall, the adjusted hazard ratios for glitazones and gliptins were similar to those in table 5, except confidence intervals were wider, and there was no longer a significant decrease in risk of heart failure and cardiovascular disease among people prescribed dual treatment with sulphonylureas and glitazones.

Discussion

We have conducted a large cohort study of risks for cardiovascular disease, heart failure, and all cause mortality associated with different diabetes drugs in people with type 2 diabetes attending for routine clinical care in the UK. Our companion paper ${ }^{27}$ presented the corresponding analysis for other complications of diabetes, including blindness, amputation, severe kidney failure, hyperglycaemia, and hypoglycaemia. The approach we have taken allows assessment of the relative benefits and hazards of diabetes drugs in a real world clinical setting for a range of clinically important outcomes. It enables analysis of treatment periods that are substantially longer than those reported in clinical trials, ${ }^{9}$ including more events than in previous similar observational studies. ${ }^{512}$

We have found clinically relevant differences between different diabetes drugs (alone and in combination) in the risk of three key outcomes-heart failure, cardiovascular disease, and death-in people with type 2 diabetes. Compared with non-use, use of glitazones was significantly associated with a decreased risk of all three outcomes (all cause mortality; heart failure, and cardiovascular disease), whereas use of gliptins was significantly associated with a decreased risk of two outcomes (all cause mortality and heart failure) but no significant change in risk of cardiovascular disease. Compared with periods of no treatment, dual treatment (ie, metformin and gliptins or metformin and glitazones) was associated with a decreased risk of all three outcomes, as was triple treatment with metformin, sulphonylureas, and either gliptins or glitazones. 


\begin{tabular}{|c|c|c|c|}
\hline \multirow[b]{2}{*}{ Treatments } & \multicolumn{3}{|c|}{ Adjusted hazard ratio $(95 \% \mathrm{Cl})$} \\
\hline & Heart failure & Cardiovascular disease & All cause mortality \\
\hline Metformin (reference) & 1.00 & 1.00 & 1.00 \\
\hline \multicolumn{4}{|l|}{ Monotherapy or no treatment: } \\
\hline No current treatment & $1.47(1.40 \text { to } 1.53)^{\star}$ & $1.31(1.27 \text { to } 1.35)^{\star}$ & $1.55(1.52 \text { to } 1.59)^{\star}$ \\
\hline Sulphonylureas & $1.47(1.37 \text { to } 1.57)^{\star}$ & $1.31(1.24 \text { to } 1.38)^{\star}$ & $1.93(1.87 \text { to } 2.00)^{\star}$ \\
\hline Insulin & $1.85(1.61 \text { to } 2.12)^{\star}$ & $1.59(1.41 \text { to } 1.80)^{\star}$ & $2.55(2.41 \text { to } 2.71)^{\star}$ \\
\hline Glitazones & $0.74(0.38$ to 1.42$) \dagger$ & $1.03(0.69$ to 1.54$) \dagger$ & $1.38(1.04$ to 1.83$) \dagger$ \\
\hline Gliptins & $1.28(0.85$ to 1.92$) \dagger$ & $1.50(1.11 \text { to } 2.02)^{\star}$ & $1.86(1.55 \text { to } 2.25)^{\star}$ \\
\hline Other diabetes drugs & $1.35(0.85$ to 2.14$) \dagger$ & $1.47(1.03 \text { to } 2.09)^{\star}$ & $1.65(1.31 \text { to } 2.08)^{\star}$ \\
\hline \multicolumn{4}{|l|}{ Dual treatment: } \\
\hline Metformin and sulphonylureas & $1.09(1.03 \text { to } 1.15)^{\star}$ & $0.99(0.95$ to 1.03$) \dagger$ & $0.96(0.93$ to 0.99$) \dagger$ \\
\hline Metformin and insulin & $1.58(1.36 \text { to } 1.83)^{\star}$ & $1.16(1.03 \text { to } 1.32)^{\star}$ & $1.18(1.07 \text { to } 1.31)^{\star}$ \\
\hline Metformin and glitazones & $0.74(0.58$ to 0.93$) \neq$ & $0.60(0.51$ to 0.70$) \neq$ & $0.86(0.74$ to 1.00$) \dagger$ \\
\hline Metformin and gliptins & $0.91(0.76$ to 1.10$) \dagger$ & 0.87 (0.77 to 0.99$) \ddagger$ & $0.80(0.71$ to 0.91$) \ddagger$ \\
\hline Metformin and other hypo & 1.08 (0.84 to 1.40$) \dagger$ & $0.96(0.80$ to 1.15$) \dagger$ & 0.72 (0.58 to 0.89$) \neq$ \\
\hline Sulphonylureas and insulin & $1.73(1.41 \text { to } 2.13)^{\star}$ & $1.54(1.26 \text { to } 1.88)^{\star}$ & $2.32(2.09 \text { to } 2.58)^{\star}$ \\
\hline Sulphonylureas and glitazones & 0.95 (0.68 to 1.31)† & $0.99(0.76$ to 1.28$) \dagger$ & $1.50(1.24 \text { to } 1.80)^{*}$ \\
\hline Sulphonylureas and gliptins & $1.29(0.96$ to 1.72$) \dagger$ & $1.27(1.00$ to 1.60$) \dagger$ & $1.44(1.23 \text { to } 1.68)^{\star}$ \\
\hline Sulphonylureas and other diabetes drugs & $2.13(1.39 \text { to } 3.28)^{\star}$ & $1.33(0.87$ to 2.03$) \dagger$ & $2.07(1.55 \text { to } 2.77)^{\star}$ \\
\hline \multicolumn{4}{|l|}{ Triple treatment: } \\
\hline Metformin, sulphonylureas, and insulin & $1.34(1.11 \text { to } 1.60)^{\star}$ & $1.24(1.08 \text { to } 1.42)^{\star}$ & $1.53(1.35 \text { to } 1.72)^{\star}$ \\
\hline Metformin, sulphonylureas, and glitazones & 0.79 (0.66 to 0.93$) \neq$ & $0.78(0.70$ to 0.87$) \ddagger$ & 0.68 (0.59 to 0.78$) \ddagger$ \\
\hline Metformin, sulphonylureas, and gliptins & $0.89(0.76$ to 1.03$) \dagger$ & $0.92(0.83$ to 1.02$) \dagger$ & $0.76(0.69$ to 0.85$) \neq$ \\
\hline Metformin, sulphonylureas, and other diabetes drugs & $0.87(0.68$ to 1.13$) \dagger$ & 0.81 (0.68 to 0.97)‡ & $0.71(0.58$ to 0.88$) \neq$ \\
\hline All other drug combinations & $1.06(0.86$ to 1.29$) \dagger$ & $1.07(0.94$ to 1.23$) \dagger$ & 1.05 (0.91 to 1.22$) \dagger$ \\
\hline \multicolumn{4}{|c|}{$\begin{array}{l}\text { *Significantly increased. } \\
\text { †Non-significant. } \\
\text { †Significantly decreased. } \\
\text { Hazard ratios adjusted for: sex; age; calendar year; duration since diagnosis of diabetes (five levels); ethnicity (nine levels); Townsend deprivation score; } \\
\text { smoking status (five levels); use of other diabetes drugs, anticoagulant thiazides, angiotensin coverting enzyme inhibitors, angiotensin receptor } \\
\text { blockers, calcium channel blockers, statins, and aspirin; previous complications (blindness, hyperglycaemia, hypoglycaemia, amputation, severe kidney } \\
\text { failure); hypertension; cardiovascular disease; atrial fibrillation; chronic renal disease; rheumatoid arthritis; valvular heart disease; peripheral vascular } \\
\text { disease; body mass index; systolic blood pressure; haemoglobin A1 ; serum creatinine level; cholesterol to high density lipoprotein cholesterol ratio. }\end{array}$} \\
\hline
\end{tabular}

However, since the use of gliptins and glitazones is usually recommended as a second line treatment in combination with other agents such as metformin, the clinical question is whether the addition of gliptins or glitazones to metformin monotherapy is associated with net benefit or net harm. Compared with metformin monotherapy, dual treatment (metformin and glitazones) and triple treatment (metformin, sulphonylureas, and glitazones) were associated with decreased risk of all three outcomes (see table 6). Dual treatment (metformin and gliptins) was associated with a decreased risk of cardiovascular disease and all cause mortality compared with metformin monotherapy. Triple treatment (metformin, sulphonylureas, and gliptins) was associated with a $24 \%$ reduced risk of all cause mortality (see table 6).

\section{Gliptins}

Our study included over 70000 person years of exposure to gliptins from over 32500 patients, which represents one of the largest studies to date, with over four times more gliptin users than in the observational study by Eurich et al..$^{20}$ Our results differ from those reported by Eurich et al, since we found that use of gliptins compared with non-use was associated with a reduction in all cause mortality. We also found that dual treatment (metformin and gliptins) and triple treatment (metformin, sulphonylureas, and gliptins) seems to be associated with a lower risk of all cause mortality compared with monotherapy with metformin. The median duration of use of gliptins in our study was 5.7 years, compared with 2.5 years in the study by Eurich et al, ${ }^{20}$ and the mean age of our cohort was 63 years compared with 52 years. ${ }^{20}$ We also had more events and more statistical power-there were 996 deaths during 71524 person years of exposure to gliptins in our study compared with 32 deaths during 11307 person years in the study by Eurich et al. ${ }^{20}$ Our findings of a reduction in risk of all cause mortality are relatively novel and deserve further investigation, especially as there was no overall reduction in cardiovascular events. Our results are consistent with another recent real world observational study, which found gliptins associated with reduced all cause mortality. ${ }^{48}$ Park et al hypothesised that their findings might reflect reduced hypoglycaemic events, although their study, like ours, was observational and susceptible to unmeasured confounding. ${ }^{48}$ In our companion paper, we reported reduced risks of hypoglycaemia among gliptin users compared with non-users, which is broadly consistent with this hypothesis. ${ }^{27}$

Our results are also broadly consistent with recent non-inferiority trials ${ }^{18}$ and meta-analyses of randomised controlled trials, reporting that various gliptins (alogliptin, dutogliptin, linagliptin, saxagliptin, 
sitagliptin, and vildagliptin) are associated with statistically significant $30-60 \%$ reductions in major adverse cardiac events and non-significant $33 \%$ and $48 \%$ reductions in all cause and cardiovascular death compared with other active drugs or placebo treatment. ${ }^{4950}$ However, Monami et al urge caution in interpreting the results because the events were not the principle endpoints, the trial duration was short, and the characteristics of patients could be different from those of patients in routine clinical practice. ${ }^{50}$ We found an inverse association for gliptins, with a 15\% lower risk of heart failure, whereas trials did not find such a strong benefit. This may reflect residual confounding owing to the observational study design or differences in study duration. However, our findings are consistent with the recently published multicentre nested case-control study, ${ }^{51}$ which also reported a $14-18 \%$ lower risk of hospital admission for heart failure with gliptins compared with other diabetes drugs. It is also consistent with a new user cohort study, which did not find a higher risk of heart failure among patients prescribed gliptins compared with other diabetes drugs. ${ }^{52}$

Some of the differences in results between our observational study and earlier clinical trials may reflect the type of gliptin studied $-80 \%$ of patients prescribed gliptins were prescribed sitagliptin in our study compared with saxagliptin in some of the trials. Currently there are too few patients prescribed linagliptin, saxagliptin, and vildagliptin to support separate analyses by individual drug, which is a limitation of the study as there may be differences between individual gliptins and their effect on haemoglobin $A 1_{c} \cdot{ }^{53}$ However, the numbers of people taking different types of gliptin is likely to increase over time, and further analyses can be undertaken once more data have accrued.

\section{Glitazones}

Our study included over 55000 person years of exposure to glitazones arising from 21308 patients. The predominant glitazone was pioglitazone, which was prescribed to $90 \%$ of glitazone users, and hence our results most closely reflect associations for pioglitazone rather than rosiglitazone (withdrawn in the UK in 2010). Our study is substantially larger than a previous UK study of 92000 people with diabetes, which finished in $2005^{4}$ and includes newer drugs available over the past decade. It supplements information from the Canadian study, ${ }^{12}$ of people aged 66 and over which compared three outcomes (heart failure, myocardial infarction, and death) among 16951 users of pioglitazone compared with 22785 users of rosiglitazone between 2002 and 2008. Our study is more recent and includes more patients prescribed pioglitazone over a longer duration (mean exposure of 4.5 years in our study compared with 294 days). It also includes more events-the Canadian study ${ }^{12}$ included 461 cases of heart failure, 273 of myocardial infarction, and 377 deaths.

We have found significant reductions in two outcomes-cardiovascular disease and all cause mortality-among users of glitazones compared with non-users (table 3). This reduction is similar in magnitude to that reported in clinical trials and meta-analyses of pioglitazone. ${ }^{911}$ In 2007, Lincoff et al reported a meta-analysis of 19 trials of pioglitazone with a treatment duration ranging from four months to 3.5 years. ${ }^{11}$ The results showed an $18 \%$ decreased risk of their composite primary outcome (risk of death, myocardial infarction, or stroke). However, we have reported a decreased risk of heart failure among users of glitazones compared with non-users. This contrasts with the increase in heart failure that occurred in other studies, without an associated increase in mortality. ${ }^{911}$ The authors of the PROactive study partially attributed this finding to a diagnostic bias due to the increase of oedema in the pioglitazone group. ${ }^{9}$ Our observational study differs from the clinical trial not only in design, size, and setting but also in the calendar time during which it was conducted and in the selection of patients. For example, the PROactive study ${ }^{9}$ selectively recruited high risk patients with pre-existing macrovascular disease, whereas our study included a more representative population from primary care. Two thirds of patients in the PROactive study ${ }^{9}$ had evidence of myocardial infarction or stroke compared with $14 \%$ in our study. It is also possible that, given the growing concerns about rosiglitazone and its subsequent withdrawal, patients with symptoms or signs suggestive of early heart failure (such as breathlessness or oedema) in our study might not have been prescribed pioglitazone or might have switched to another diabetes drug.

\section{Other diabetes drugs}

Although our research question focuses on associations between gliptins and glitazones and adverse clinical outcomes, for comparison we have results for other diabetes drugs. Overall, metformin monotherapy was associated with reduced risks of all cause mortality, heart failure, and cardiovascular disease compared with non-use. This is important because metformin is generally recommended as the first line diabetes drug and is commonly used in combinations with other drugs. Sulphonylureas were associated with an increased risk of all cause mortality both in the main analysis and in the sensitivity analyses restricted to new users of sulphonylureas. Monotherapy with sulphonylureas was also associated with an increased risk of cardiovascular disease and as triple treatment with metformin and insulin was associated with an increased risk of heart failure compared with metformin alone. These unfavourable results are consistent with some studies linking sulphonylureas with increased adverse cardiovascular events, ${ }^{5}$ but not all studies. ${ }^{26}$ Further research into the safety of sulphonylureas compared with other types of diabetes drugs is warranted. However, this research needs to distinguish between individual types of sulphonylureas, as different individual drugs have different mortality risks. ${ }^{54}$

As in our companion paper, ${ }^{27}$ we excluded prevalent users of insulin at baseline but included in the analysis those patients subsequently prescribed insulin because insulin is part of the treatment ladder and some of these people will also have had other drugs of interest during 
follow-up. Although insulin was not the primary drug of interest, patients prescribed insulin had higher risks of all three outcomes, despite adjustment for higher levels of comorbidity. It is unlikely that this increased risk was a direct result of treatment with insulin. Instead, residual confounding and reverse causality could have occurred-that is, the insulin treated group was at much higher risk of complications than the groups treated with diet or oral drugs, and these result in their apparently worse outcomes and not their treatment with insulin. For example, in table 2, the insulin treated group had the highest haemoglobin $\mathrm{A}_{\mathrm{c}}$ and creatinine values before treatment, although both factors were adjusted for in the analyses. An alternative explanation could be that patients with symptoms that indicated cardiovascular disease or heart failure were prescribed insulin rather than glitazones or gliptins before subsequently having a diagnosis of these conditions.

\section{Strengths and limitations of this study Generalisability}

This is a large study based on an ethnically diverse contemporaneous, representative population of people with type 2 diabetes during an eight year study period. We included all eligible patients to minimise selection bias. Hence we think the results are likely to be generalisable to similar populations of people with type 2 diabetes. Although our observational study has limitations inherent in its design, it also has advantages over meta-analyses of clinical trials as these tend to be limited by ascertainment and reporting of events, short follow-up, lack of time to event data, and insufficient power to report on rare cardiovascular events. ${ }^{23}$

\section{Clinical outcomes}

Strengths of our analysis are the inclusion of hard clinical endpoints of cardiovascular disease, heart failure, and death based on clinical diagnoses recorded on at least one of three linked electronic data sources. Use of all three linked data sources was designed to minimise under-ascertainment of outcomes, which would otherwise lead to under-estimation of absolute risks. The cardiovascular disease and heart failure outcomes are based on clinical diagnoses made by the treating clinician rather than formally adjudicated events as would occur in a clinical trial. Although it is possible that some patients were recorded as having heart failure or cardiovascular disease who did not have this condition, such misclassification will not have affected the mortality outcome. UK general practices have good levels of accuracy and completeness in recording clinical diagnoses and prescribed drugs. ${ }^{55}$ Also, the diagnostic validity of such diagnoses in general practice has been shown to be high. ${ }^{56}$ Possible ascertainment bias of outcomes is unlikely to vary according to the type of diabetes drug prescribed so would not explain the associations we found.

\section{Exposure to diabetes drugs}

We had detailed information on use of diabetes drugs prescribed throughout the follow-up period, enabling us to develop a detailed categorisation of drug exposure time into 21 different treatment groups, including combinations of treatments. Recording of prescriptions issued in UK general practices has high levels of completeness. ${ }^{57}$ We ascertained patient characteristics, concurrent drugs, clinical values, and diagnoses at the beginning of each treatment period. This enabled us to account for switching between different treatments or treatment combinations, making adjustments for a large number of potential confounders. We undertook a time varying analysis, which analysed different types of monotherapy, dual treatment, and triple treatment over the study period. This reflects real world prescribing patterns over a long duration, allowing multiple comparisons not only between drugs but also between different combinations of drugs compared with untreated periods of time (diet only treatment). Our study analysed prescribed drugs rather than the drug actually taken by the patients, although renewal of prescriptions is likely to indicate drug use, as patients need to initiate repeat prescriptions. This could result in misclassification of exposure if patients were prescribed drugs that they did not actually take and could underestimate associations between use of diabetes drugs and clinical outcomes. Unlike previous studies, we have included comparisons of risk against periods of no treatment, ${ }^{5}$ which is important as about $40 \%$ of people with type 2 diabetes are managed without diabetes drugs throughout follow-up. Limitations include lack of analyses for different subtypes of each type of drug and for different dose levels.

\section{Assessment of other types of bias}

Other types of bias that can affect observational studies include recall bias, indication bias, and channelling bias. Recall bias will not have occurred as data on prescriptions for diabetes drugs and confounding variables were recorded before the clinical outcomes. We restricted the study population to people with type 2 diabetes to limit indication bias (ie, bias that occurs when people are prescribed drugs for a condition that is itself associated with the risk of the adverse event under consideration). We used an incident user design to reduce, but not eliminate, confounding and biases that can otherwise arise from adjustment for intermediate characteristics in the causal path. ${ }^{36}$ There were some differences at baseline between patients prescribed different treatment groups (tables 1 and 2), although these were predominantly increased levels of comorbidities for insulin and lower levels of concurrent use of drugs (such as statins and aspirin) for metformin. To reduce channelling bias (where the choice of a particular drug is influenced by patient characteristics), we adjusted for a wide range of potential confounding variables. This included demographic characteristics (age, sex, ethnicity, and deprivation), different comorbidities, clinical values (including haemoglobin $\mathrm{A}_{\mathrm{c}}$, body mass index, blood pressure, creatinine level, and cholesterol to high density lipoprotein cholesterol ratio), and concurrent drugs. However, we are unable to exclude the possibility of residual confounding because other unmeasured 
patient characteristics might have affected the selection of diabetes drug treatment.

Although randomised controlled trials of diabetes drugs are not influenced by residual confounding, they tend to be small, of short duration, and might not report on relevant clinical outcomes. An alternative design would be an observational study of a cohort of patients specifically assembled for the purpose rather than using routinely collected data as in our study. Studies using routinely collected data are susceptible to missing data, although in our study over $99 \%$ of patients had smoking status recorded, $87 \%$ had ethnic group recorded, and over $82 \%$ had complete data for all five clinical values (table 2). We also used multiple imputation to deal with missing data. Other problems with routine data include coding errors and variable timing between measurements of risk factors because of differences in when patients present to their general practitioner. Advantages of using routinely collected data rather than a purposeful cohort include size, efficiency, better generalisability, and less susceptibility to selection bias or attrition bias.

We fitted several different models and carried out sensitivity analyses that showed some heterogeneity of results with variations in point estimates. The results are therefore sensitive to the assumptions made in the study design and modelling and have uncertainty; however, our findings were generally consistent across the different analyses for glitazones and gliptins.

\section{Conclusions}

We have found clinically important differences in risk of cardiovascular disease, heart failure, and all cause mortality between different diabetes drugs alone and in combination compared with no drug treatment. Overall, use of gliptins or glitazones was associated with a decreased risk of heart failure, cardiovascular disease, and all cause mortality compared with non-use of these drugs. These results, which do not account for levels of adherence or dosage information and which are subject to confounding by indication, may have implications for prescribing of diabetes drugs.

We acknowledge the contribution of the practices that contribute to QResearch and Egton Medical Information Systems (EMIS), and the University of Nottingham for expertise in establishing, developing, and supporting the database. The data from hospital episode statistics used in this analysis are re-used by permission from the Health and Social Care Information Centre who retain the copyright. We thank the Office for National Statistics for providing the mortality data. ONS bear no responsibility for the analysis or interpretation of the data.

Contributors: JH-C initiated the study, undertook the literature review, data extraction, data manipulation, and primary data analysis, and wrote the first draft of the paper. CC contributed to the design, analysis, data manipulation, interpretation, and drafting of the paper $\mathrm{JH}-\mathrm{C}$ had access to all the data for this project. J $\mathrm{H}-\mathrm{C}$ is the guarantor. Funding: This study received no external funding.

Competing interests: All authors have completed the ICMJE uniform disclosure form at www.icmje.org/coi_disclosure.pdf (available on request from the corresponding author) and declare: $\mathrm{JH}-\mathrm{C}$ is professor of clinical epidemiology at the University of Nottingham and codirector of QResearch, a not-for-profit organisation, which is a joint partnership between the University of Nottingham and Egton Medical Information Systems (leading commercial supplier of IT for $60 \%$ of general practices in the UK). JH-C is also a paid director of ClinRisk, which produces open and closed source software to ensure the reliable and updatable implementation of clinical risk algorithms within clinical computer systems to help improve patient care. CC is professor of Medical Statistics in Primary Care at the University of Nottingham and a paid consultant statistician for ClinRisk. This work and any views expressed within it are solely those of the coauthors and not of any affiliated bodies or organisations.

Ethical approval: This project was reviewed in accordance with the QResearch agreement with Trent MultiCentre Ethics Committee (reference 03/4/021).

Data sharing: The patient level data from the QResearch are specifically licensed according to its governance framework. See www. qresearch.org for further details.

Transparency: The lead author $(\mathrm{JH}-\mathrm{C})$ affirms that the manuscript is an honest, accurate, and transparent account of the study being reported, that no important aspects of the study have been omitted, and that any discrepancies from the study as planned have been explained.

This is an Open Access article distributed in accordance with the terms of the Creative Commons Attribution (CC BY 3.0) license, which permits others to distribute, remix, adapt and build upon this work, for commercial use, provided the original work is properly cited. See: http://creativecommons.org/licenses/by/3.0/.

1 Health and Social Care Information Centre. National Diabetes Audit 2012-2013 Report 2 Complications and Mortality. 2014

2 Khan SS, Butler J, Gheorghiade M. Management of comorbid diabetes mellitus and worsening heart failure. JAMA 2014;311:2379-80. doi:10.1001/jama.2014.4115.

3 Scirica BM, Bhatt DL, Braunwald E, et al. SAVOR-TIMI 53 Steering Committee and Investigators. Saxagliptin and cardiovascular outcomes in patients with type 2 diabetes mellitus. N Engl J Med 2013;369:1317-26. doi:10.1056/NEJMoa1307684.

4 Home PD, Pocock SJ, Beck-Nielsen H, et al. RECORD Study Team. Rosiglitazone evaluated for cardiovascular outcomes in oral agent combination therapy for type 2 diabetes (RECORD): a multicentre, randomised, open-label trial. Lancet 2009;373:2125-35. doi:10.1016/ S0140-6736(09)60953-3.

5 Tzoulaki I, Molokhia M, Curcin V, Little MP, Millett CJ, Ng A, et al. Risk of cardiovascular disease and all cause mortality among patients with type 2 diabetes prescribed oral antidiabetes drugs: retrospective cohort study using UK general practice research database. BM) 2009;339:b4731.

6 NICE. Guidance on rosiglitazone for type 2 diabetes mellitus. National Institute for Clinical Excellence, 2000.

7 Cohen D. Insiders criticise FDA's decision not to withdraw rosiglitazone. BMJ 2010;341:c5333.

8 Psaty BM, Furberg CD. The record on rosiglitazone and the risk of myocardial infarction. N Engl / Med 2007;357:67-9. doi:10.1056/ NEJMe078116.

9 Dormandy JA, Charbonnel B, Eckland DJ, et al. PROactive Investigators. Secondary prevention of macrovascular events in patients with type 2 diabetes in the PROactive Study (PROspective pioglitAzone Clinical Trial In macroVascular Events): a randomised controlled trial. Lancet 2005;366:1279-89. doi:10.1016/ S0140-6736(05)67528-9.

10 Scheen AJ. Outcomes and lessons from the PROactive study. Diabetes Res Clin Pract 2012:98:175-86. doi:10.1016/i.diabres.2012.09.001.

11 Lincoff AM, Wolski K, Nicholls SJ, Nissen SE. Pioglitazone and risk of cardiovascular events in patients with type 2 diabetes mellitus: a meta-analysis of randomized trials. JAMA 2007;298:1180-8. doi:10.1001/jama.298.10.1180.

12 Juurlink DN, Gomes T, Lipscombe LL, Austin PC, Hux JE, Mamdani MM Adverse cardiovascular events during treatment with pioglitazone and rosiglitazone: population based cohort study. BMJ 2009;339:b2942.

13 Graham DJ, Ouellet-Hellstrom R, MaCurdy TE, et al. Risk of acute myocardial infarction, stroke, heart failure, and death in elderly Medicare patients treated with rosiglitazone or pioglitazone. JAMA 2010;304:411-8. doi:10.1001/jama.2010.920.

14 Lewis JD, Ferrara A, Peng T, et al. Risk of bladder cancer among diabetic patients treated with pioglitazone: interim report of a longitudinal cohort study. Diabetes Care 2011;34:916-22. doi:10.2337/dc10-1068.

15 Inzucchi SE, Bergenstal RM, Buse JB, et al. Management of hyperglycaemia in type 2 diabetes: a patient-centered approach. Position statement of the American Diabetes Association (ADA) and the European Association for the Study of Diabetes (EASD). Diabetologia 2012;55:1577-96. doi:10.1007/s00125-012-2534-0.

16 Karagiannis T, Boura P, Tsapas A. Safety of dipeptidyl peptidase 4 inhibitors: a perspective review. Ther Adv Drug Saf 2014;5:138-46. doi:10.1177/2042098614523031.

17 White WB, Cannon CP, Heller SR, et al. EXAMINE Investigators. Alogliptin after acute coronary syndrome in patients with type 2 diabetes. N Engl/ Med 2013;369:1327-35. doi:10.1056/ NEIMoa1305889. 
18 Green JB, Bethel MA, Armstrong PW, Buse JB, Engel SS, Garg J, et al. Effect of sitagliptin on cardiovascular outcomes in type 2 diabetes. New Engl / Med 2015:373:232-42.

19 Wang KL, Liu CJ, Chao TF, et al. Sitagliptin and the risk of hospitalization for heart failure: a population-based study. Int J Cardiol 2014:177:86-90. doi:10.1016/j.ijcard.2014.09.038.

20 Eurich DT, Simpson S, Senthilselvan A, Asche CV, Sandhu-Minhas JK, McAlister FA. Comparative safety and effectiveness of sitagliptin in patients with type 2 diabetes: retrospective population based cohort study. BM/ 2013;346:f2267. doi:10.1136/bmj.f2267.

21 Engel SS, Golm GT, Shapiro D, Davies MJ, Kaufman KD, Goldstein BJ. Cardiovascular safety of sitagliptin in patients with type 2 diabetes mellitus: a pooled analysis. Cardiovasc Diabetol 2013;12:3. doi:10.1186/1475-2840-12-3.

22 Diamond GA, Bax L, Kaul S. Uncertain effects of rosiglitazone on the risk for myocardial infarction and cardiovascular death. Ann Intern Med 2007:147:578-81. doi:10.7326/0003-4819-147-8-20071016000182

23 Hernandez AV, Walker E, Ioannidis JP, Kattan MW. Challenges in meta-analysis of randomized clinical trials for rare harmful cardiovascular events: the case of rosiglitazone. Am Heart j 2008;156:23-30. doi:10.1016/j.ahj.2008.03.002.

24 Department of Health and Human Services FDA, Center for Drug Evaluation and Research. Guidance for industry: diabetes mellitus-evaluating cardiovascular risk in new antidiabetic therapies to treat type 2 diabetes. 2008

25 European Medicine Agency CfMPfHU. Guideline on clinical investigation of medicinal products in the treatment of diabetes mellitus. 2010.

26 Bell DS. Do sulfonylurea drugs increase the risk of cardiac events? CMAI 2006;174:185-6. doi:10.1503/cmaj.051237.

27 Hippisley-Cox J, Coupland C. Diabetes treatments and risk of amputation, blindness, severe kidney failure, hyperglycaemia, and hypoglycaemia: open cohort study in primary care. BM 2016;352:i1450. doi:10.1136/bmj.i1450

28 Wikipedia. Readcodes 2015 http://en.wikipedia.org/wiki/ Read_code.

29 Hippisley-Cox J, Coupland C. Risk of myocardial infarction in patients taking cyclo-oxygenase- 2 inhibitors or conventional non-steroidal anti-inflammatory drugs: population based nested case-control analysis. BMJ 2005;330:1366-74. doi:10.1136/bmj.330.7504.1366.

30 Hippisley-Cox J, Coupland C, Logan R. Risk of adverse gastrointestinal outcomes in patients taking cyclo-oxygenase-2 inhibitors or conventional non-steroidal anti-inflammatory drugs: population based nested case-control analysis. BMJ 2005;331:1310-6. doi:10.1136/bmj.331.7528.1310.

31 Hippisley-Cox J, Coupland C. Unintended effects of statins in men and women in England and Wales: population based cohort study using the QResearch database. BM/ 2010;340:c2197. doi:10.1136/bmj.c2197.

32 Parker C, Coupland C, Hippisley-Cox J. Antipsychotic drugs and risk of venous thromboembolism: nested case-control study. BMJ 2010;341:c4245. doi:10.1136/bmj.c4245

33 Vinogradova Y, Coupland C, Hippisley-Cox J. Exposure to bisphosphonates and risk of gastrointestinal cancers: series of nested case-control studies with QResearch and CPRD data. BM 2013;346:f114. doi:10.1136/bmj.f114.

34 Coupland C, Hill T, Morriss R, Arthur A, Moore M, Hippisley-Cox J. Antidepressant use and risk of suicide and attempted suicide or self harm in people aged 20 to 64 : cohort study using a primary care database. BMJ 2015;350:h517. doi:10.1136/bmj.h517.

35 Hippisley-CoxJ, Pringle M. Prevalence, care, and outcomes for patients with diet-controlled diabetes in general practice: cross sectional survey. Lancet 2004;364:423-8. doi:10.1016/ S0140-6736(04)16765-2.

36 Johnson ES, Bartman BA, Briesacher BA, et al. The incident user design in comparative effectiveness research. Pharmacoepidemiol Drug Saf 2013;22:1-6. doi:10.1002/pds.3334.

37 Hippisley-CoxJ, Coupland C, Vinogradova Y, et al. Predicting cardiovascular risk in England and Wales: prospective derivation and validation of QRISK2. BMJ 2008;336:1475-82. doi:10.1136/ bmj.39609.449676.25.
38 Clarke PM, Gray AM, Briggs A, et al. UK Prospective Diabetes Study (UKDPS) Group. A model to estimate the lifetime health outcomes of patients with type 2 diabetes: the United Kingdom Prospective Diabetes Study (UKPDS) Outcomes Model (UKPDS no. 68) Diabetologia 2004;47:1747-59. doi:10.1007/s00125-004-1527-z.

39 Davis TME, Coleman RL, Holman RR. UKPDS Group. Ethnicity and long-term vascular outcomes in Type 2 diabetes: a prospective observational study (UKPDS 83). Diabet Med 2014;31:200-7. doi:10.1111/dme.12353.

40 Nichols GA, Gullion CM, Koro CE, Ephross SA, Brown JB. The incidence of congestive heart failure in type 2 diabetes: an update. Diabetes Care 2004; 27:1879-84. doi:10.2337/diacare.27.8.1879.

41 Stratton IM, Adler Al, Neil HA, et al. Association of glycaemia with macrovascular and microvascular complications of type 2 diabetes (UKPDS 35): prospective observational study. BMJ 2000;321:405-12. doi:10.1136/bmj.321.7258.405.

42 Andersen PK, Geskus RB, de Witte T, Putter H. Competing risks in epidemiology: possibilities and pitfalls. Int J Epidemiol 2012;41:861-70. doi:10.1093/ije/dyr213.

43 Lau B, Cole SR, Gange SJ. Competing risk regression models for epidemiologic data. Am J Epidemiol 2009;170:244-56. doi:10.1093/ aje/kwp107.

44 Pintilie M. Analysing and interpreting competing risk data. Stat Med 2007:26:1360-7. doi:10.1002/sim.2655.

45 Steyerberg EW, van Veen M. Imputation is beneficial for handling missing data in predictive models. J Clin Epidemiol 2007;60:979. doi:10.1016/j.jclinepi.2007.03.003.

46 Moons KGM, Donders RART, Stijnen T, Harrell FE Jr. Using the outcome for imputation of missing predictor values was preferred. J Clin Epidemiol 2006;59:1092-101. doi:10.1016/j.jclinepi.2006.01.009.

47 Schafer JL, Graham JW. Missing data: our view of the state of the art. Psychol Methods 2002;7:147-77. doi:10.1037/1082-989X.7.2.147.

48 Park HE, Jeon J, Hwang IC, et al. Effect of dipeptidyl peptidase-4 inhibitor on all-cause mortality and coronary revascularization in diabetic patients. J Cardiovasc Ultrasound 2015;23:233-43. doi:10.4250/jcu.2015.23.4.233.

49 Patil HR, Al Badarin FJ, Al Shami HA, et al. Meta-analysis of effect of dipeptidyl peptidase- 4 inhibitors on cardiovascular risk in type 2 diabetes mellitus. Am J Cardiol 2012;110:826-33. doi:10.1016/j. amjcard.2012.04.061.

50 Monami M, Dicembrini I, Martelli D, Mannucci E. Safety of dipeptidyl peptidase-4 inhibitors: a meta-analysis of randomized clinical trials. Curr Med Res Opin 2011;27(Suppl 3):57-64. doi:10.1185/03007995 .2011 .602964$.

51 Filion KB, Azoulay L, Platt RW, et al. CNODES Investigators. A multicenter observational study of incretin-based drugs and heart failure. N Engl M Med 2016;374:1145-54. doi:10.1056/ NEJMoa1506115.

52 Toh S, Hampp C, Reichman ME, et al. Risk for hospitalized heart failure among new users of saxagliptin, sitagliptin, and other antihyperglycemic drugs: a retrospective cohort study. Ann Intern Med 2016;164:705-14. doi:10.7326/M15-2568.

53 Esposito K, Chiodini P, Maiorino MI, et al. A nomogram to estimate the $\mathrm{HbA1}$ c response to different DPP-4 inhibitors in type 2 diabetes: a systematic review and meta-analysis of 98 trials with 24163 patients. BMJ Open 2015;5:e005892. doi:10.1136/bmjopen-2014-005892.

54 Simpson SH, Lee J, Choi S, Vandermeer B, Abdelmoneim AS, Featherstone TR. Mortality risk among sulfonylureas: a systematic review and network meta-analysis. Lancet Diabetes Endocrinol 2015;3:43-51. doi:10.1016/S2213-8587(14)70213-X.

55 Majeed A. Sources, uses, strengths and limitations of data collected in primary care in England. Health Stat Q 2004;(21):5-14.

56 Meier CR, Derby LE, Jick SS, Vasilakis C, Jick H. Antibiotics and risk of subsequent first-time acute myocardial infarction. JAMA 1999:281:427-31. doi:10.1001/jama.281.5.427.

57 Majeed A. Sources, uses, strengths and limitations of data collected in primary care in England. HSQ, 2004: 21.

(c) BMJ Publishing Group Ltd 2016

Supplementary file: additional information 